\title{
A NOVEL RP-HPLC METHOD FOR THE DETECTION AND QUANTIFICATION OF CLARITHROMYCIN OR SPIRAMYCIN IN BULK DRUG SAMPLES AND DOSAGE FORMS
}

\author{
RUNAKO MASLINE KATSIDZIRAa, ANITA WESSELS ${ }^{\mathrm{b}}$, MARIQUE AUCAMPa ${ }^{*}$ \\ aCentre of Excellence for Pharmaceutical Sciences, North-West University, Private Bag X6001, Potchefstroom, 2520, South Africa, \\ bDepartment of Pharmaceutical Chemistry, School of Pharmacy, Faculty of Health Sciences, North-West University, Private Bag X6001, \\ Potchefstroom, 2520, South Africa \\ Email: Marique.aucamp@nwu.ac.za
}

Received: 05 Sep 2016 Revised and Accepted: 24 Oct 2016

\section{ABSTRACT}

Objective: This study was aimed at developing an HPLC method that would be suitable and sufficiently robust to analyze clarithromycin or spiramycin from bulk materials, amorphous solid dispersions as well as when included into solid dosage forms.

Methods: $\mathrm{A} \mathrm{C}_{8}$ column $(250 \times 4.6 \mathrm{~mm}, 5 \mu \mathrm{m})$ was used as stationary phase, the mobile phase consisted of $0.1 \mathrm{M}$ dipotassium hydrogen orthophosphate buffer ( $\mathrm{pH} 6.0)$ and acetonitrile in a 50:50 (\% v/v) ratio. The flow rate was set to $0.5 \mathrm{ml} / \mathrm{min}$. UV detection of $210 \mathrm{~nm}$ was used for clarithromycin and $232 \mathrm{~nm}$ for spiramycin. Ambient column and sample tray temperatures were used.

Results: The method proved to be suitable for the detection of both macrolide antibiotics in bulk samples, as part of amorphous solid dispersions as well as in dosage forms. The isocratic elution was rapid. The method was validated in terms of system suitability, limits of detection (LOD), limit of quantification (LOQ), accuracy, precision, linearity, and specificity. This method showed linearity across the concentration range of 4.0-5000.0 $\mu \mathrm{g} / \mathrm{ml}$ for both antibiotics.

Conclusion: The developed method showed to be a simple and sufficiently sensitive method for the detection and quantification of either clarithromycin or spiramycin from samples that might contain even very small quantities of the antibiotics.

Keywords: Clarithromycin, Spiramycin, RP-HPLC

(C) 2016 The Authors. Published by Innovare Academic Sciences Pvt Ltd. This is an open access article under the CC BY license (http://creativecommons.org/licenses/by/4. 0/] DOI: http://dx.doi.org/10.22159/ijpps.2016v8i12.15058

Recent studies have shown that opportunistic infections of patients suffering from HIV are the cause of $90 \%$ of patient morbidity and mortality $[1,2]$. The most prevalent and life-threatening opportunistic infections among people living with HIV in different populations include Mycobacterium tuberculosis, Pneumocystis jirovecii pneumonia, Mycobacterium avium complex (MAC) and Cryptosporidiosis [1, 3]. Azithromycin and clarithromycin are currently the two macrolide antibiotics of choice prescribed for the prophylaxis and treatment of MAC opportunistic infections in HIV patients [4]. Cryptosporidiosis is a life-threatening infection that is very difficult to treat since it causes cholera-like diarrhoea with the profuse daily fluid loss of about 17 liters [5]. Spiramycin is one of the macrolide antibiotics recommended for treating cryptosporidiosis among immunosuppressed individuals [6, 7]. Considering the global dilemma of antimicrobial resistance, there is currently a renewed focus on antibiotics that were not usually the drug of choice for the treatment of certain infections. Spiramycin is one such drug. During our research on clarithromycin and spiramycin, we identified the need for a suitable and single HPLC method that could be used for the identification and analysis of both drugs. Especially, considering that the British Pharmacopoeia (BP) only reports on an HPLC method that is suitable for the analysis of spiramycin from veterinary formulations [8]. No another pharmacopeia contains an analytical method for spiramycin. Furthermore, the methods included in both the BP and the United States Pharmacopoeia [9] for clarithromycin uses high buffer concentrations, and those methods lead to long HPLC run times.

Clarithromycin is classified as a semi-synthetic antibiotic which forms part of the macrolide group. This antibiotic is derived from erythromycin but differs in the fact that the 0-methyl group has been substituted for a hydroxyl group at position six of the lactone ring (fig. 1a) [10]. Spiramycin consists of a 16-membered lactone (platenolide), two amino sugars (D-mycaminose and D-forosamine) and one neutral sugar (L-mycarose) (fig.1b). Spiramycin has three major (I, II, III), three minor components (IV, V, VI) and two other additional spiramycins 18-deoxy-18-dihydrospiramycin (DSPM) and 17-methylenespiramycin. Though spiramycin I is shown to be the main component, the quantity of each component varies according to the manufacturer [11-13]. (a)

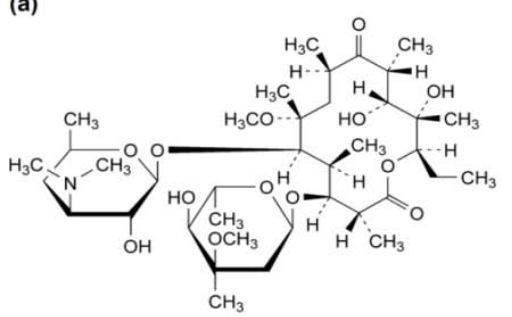

(b)

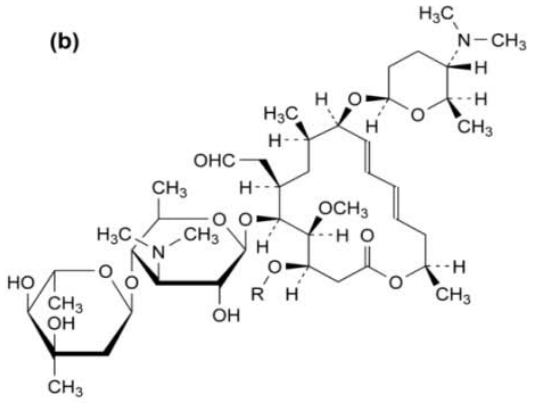

Fig. 1: Molecular structure of (a) clarithromycin and (b) spiramycin [8] 
The objective of this study was to develop an easy, cost-effective but sufficiently robust RP-HPLC method for the detection of clarithromycin or spiramycin. The rationale for this was that the current methods that are available in the literature for both drugs use high concentration buffers as part of the mobile phases and in the instance of clarithromycin, gradient elution is being applied. Therefore, this is a simple method with the ability to accurately detect and quantify both drugs, thereby making it very useful for laboratories that need to analyze both macrolide antibiotics.

Clarithromycin working standard (97.7\% purity) and spiramycin (purity of $94.9 \%$, only spiramycin I) were purchased from SigmaAldrich (Johannesburg, South Africa) and DB Fine Chemicals (Johannesburg, South Africa). HPLC grade acetonitrile, potassium dihydrogen orthophosphate and hydrochloric acid (32\%) were purchased from ACE Chemicals (Johannesburg, South Africa). The pharmaceutical dosage form used during specificity testing was Clacee $^{\circledR} 250$ mg tablets (Aspen Pharmacare, South Africa). In the case of spiramycin, no commercial product was available for purchase and therefore a mixture of typical pharmaceutical excipients was made. This mixture constituted of microcrystalline cellulose, polyvinylpyrrolidone (PVP) K 30, magnesium stearate, talc and croscarmellose sodium. All the excipients used were a kind donation from the Department of Pharmaceutics of the School of Pharmacy, North-West University, and Potchefstroom, South Africa.

A Shimadzu (Kyoto, Japan) UFLC (LC-20AD) chromatographic system, equipped with an SIL-20AC autosampler fitted with a sample cooler, a UV/VIS PDA detector (SPD-M20) and an LC-20AD solvent delivery module was used during the method development and validation. A Phenomenex ${ }^{\circledR}$ Luna C8 $5 \mu \mathrm{m}, 250 \times 4.6 \mathrm{~mm}$ column was used as stationary phase. The mobile phase consisted of $0.1 \mathrm{M}$ phosphate buffer ( $\mathrm{pH}$ adjusted to 6.0 with $0.1 \mathrm{M} \mathrm{HCl}$ ) and acetonitrile in a ratio of $50 / 50 \% \mathrm{v} / \mathrm{v}$. Isocratic elution was used with a flow rate of $0.5 \mathrm{ml} / \mathrm{min}$. An injection volume of $10 \mu \mathrm{l}$ was used for the analysis and validation of clarithromycin while an injection volume of $2 \mu \mathrm{l}$ was found to be suitable for spiramycin. For the detection of clarithromycin, a wavelength of $210 \mathrm{~nm}$ was used while spiramycin was detected at $232 \mathrm{~nm}$ [9]. For both antibiotics, stock solutions were prepared by separately and accurately weighing $50 \mathrm{mg}$ of drug and diluting it to $10 \mathrm{ml}$ with mobile phase. This resulted in a stock solution of $5000.0 \mu \mathrm{g} / \mathrm{ml}$, for each drug. Aliquots of these stock solutions were then diluted with mobile phase to obtain standard solutions with concentrations ranging from 4.0$5000.0 \mu \mathrm{g} / \mathrm{ml}$. Each standard solution was filtered using a $0.45 \mu \mathrm{m}$ PVDF filter into HPLC vials.

During the preparation of product sample for the testing of the specificity of clarithromycin, 10 tablets were weighed and grinded using a mortar and pestle. In the case of spiramycin, a sample was prepared as discussed previously described. For each drug sufficient sample powder was weighed, equivalent to result in a final drug concentration of $1000 \mu \mathrm{g} / \mathrm{ml}$. Each sample was diluted with mobile phase. The flasks were shaken for 10 min using an ultrasonic shaker. Thereafter each sample was filtered through a $0.45 \mu \mathrm{m}$ PVDF filter into HPLC vials.

The method was validated as specified by the ICH guideline on the validation of analytical procedures (ICH) [14]. Linearity, range, precision, accuracy, recovery, specificity, limit of detection (LOD) and limit of quantification (LOQ) were the validation parameters. For each drug, eight standard solutions with concentrations over the stated working range were analyzed in duplicate. This was done during two different times by two different analysts. From the obtained data, regression plots of peak area versus drug concentration provided linear regression data as stipulated in table 1.

Table 1: Validation parameters determined during method validation for the detection and quantification of clarithromycin and spiramycin

\begin{tabular}{lll}
\hline Validation parameter* & Clarithromycin & Spiramycin \\
\hline Linearity range $(\mu \mathrm{g} / \mathrm{ml})$ & $4.0-5000.0$ & $4.0-5000$ \\
Correlation coefficient $\left(r^{2}\right)$ & 0.9999 & 0.9999 \\
Regression equation & $\mathrm{y}=505.55 \mathrm{x}-9083.33$ & $\mathrm{y}=14801 \mathrm{x}-276251$ \\
Recovery $(\%)( \pm \% \mathrm{RSD})$ & $99.95 \pm 1.25 \%$ & $99.65 \pm 1.02 \%$ \\
$\mathrm{LOD}(\mu \mathrm{g} / \mathrm{ml})( \pm \% \mathrm{RSD})$ & $4.0( \pm 6.6 \%)$ & $1.5( \pm 12.9 \%)$ \\
$\mathrm{LOQ}(\mu \mathrm{g} / \mathrm{ml})( \pm \% \mathrm{RSD})$ & $16.0( \pm 0.36 \%)$ & $8.0( \pm 0.13 \%)$ \\
\hline
\end{tabular}

${ }^{*}$ The validation parameters were determined from the analysis of eight standard solutions $(\mathrm{n}=8)$ over a concentration range of 4.0-5000.0 $\mu \mathrm{g} / \mathrm{ml}$. \%RSD: Percentage relative standard deviation. LOD: Limit of detection, LOQ: Limit of quantification.

The recovery obtained with this method proved to be acceptable for both drugs, due to the fact that the recovery was between the limits of $98.0-102.0 \%$. The determined LOD and LOQ limits for this method also proved to be acceptable with very small concentration levels of both drugs being detectable and quantifiable. The accuracy of the proposed method was tested at clarithromycin concentration levels of $250.0 \mu \mathrm{g} / \mathrm{ml}$ and $1000.0 \mu \mathrm{g} / \mathrm{ml}$. The recovery for clarithromycin was determined to be between $98.32-101.64 \%$, with a mean recovery of $99.95 \%$ and a percentage relative standard deviation (\%RSD) of $1.25 \%$. For spiramycin concentration levels of $250.0 \mu \mathrm{g} / \mathrm{ml}$ and $1030.0 \mu \mathrm{g} / \mathrm{ml}$ was used for accuracy testing. The results showed recovery between $98.21-101.10 \%$, with a mean recovery of $99.65 \%( \pm 1.02 \%)$. From these results, it can be concluded that the method delivers accurate results. The precision of the method was investigated through determination of repeatability and intermediate precision. The repeatability for both drugs was determined at concentration levels, 200.0, 500.0 and $1025.0 \mu \mathrm{g} / \mathrm{ml}$, the samples were analyzed in triplicate (table 2).

Table 2: Summary of repeatability data obtained for clarithromycin and spiramycin

\begin{tabular}{lll}
\hline $\begin{array}{l}\text { Theoretical concentration } \\
(\boldsymbol{\mu g} / \mathbf{m l})\end{array}$ & $\begin{array}{l}\text { Mean clarithromycin concentration } \\
(\boldsymbol{\mu g} / \mathbf{m l}) \pm \% \mathbf{R S}^{*}\end{array}$ & $\begin{array}{l}\text { Mean spiramycin concentration } \\
(\boldsymbol{\mu g} / \mathbf{m l}) \pm \% \mathbf{R S D}^{*}\end{array}$ \\
\hline 200.0 & $210.44( \pm 0.05)$ & $213.43( \pm 0.56)$ \\
500.0 & $511.16( \pm 0.62)$ & $513.88( \pm 0.18)$ \\
1025.0 & $1030.45( \pm 0.84)$ & $1020.73( \pm 0.28)$ \\
\hline
\end{tabular}

${ }^{*}$ Each reported value is the mean $\pm \%$ RSD of $\mathrm{n}$ observations. For repeatability, $\mathrm{n}$ is $3 . \%$ RSD denotes the percentage standard deviation

The intermediate precision was measured during three different sampling times. Samples were prepared by different analysts as well and analyzed in duplicate. The resulting data is presented in table 3.
The \% RSD for these determinations were not more than $5.0 \%$ and were therefore deemed as sufficient proof of the precision of this method. 
Table 3: Summary of intermediate precision data obtained for both drugs. Samples were analysed on different days, by different analysts

\begin{tabular}{lll}
\hline $\begin{array}{l}\text { Theoretical concentration } \\
(\boldsymbol{\mu g} / \mathbf{m l})\end{array}$ & $\begin{array}{l}\text { Mean clarithromycin concentration } \\
(\boldsymbol{\mu g} / \mathbf{m l}) \pm \% \text { RSD }\end{array}$ & $\begin{array}{l}\text { Mean spiramycin concentration } \\
(\boldsymbol{\mu g} / \mathbf{m l}) \pm \% \mathrm{RSD}\end{array}$ \\
\hline 1000.0 & $(1) 999.29( \pm 0.11 \%)$ & (1) $1017.43( \pm 1.45 \%)$ \\
& $(2) 995.53( \pm 1.91 \%)$ & (2) $1018.05( \pm 0.59 \%)$ \\
& (3) $1018.89( \pm 0.58 \%)$ & (3) $1019.82( \pm 0.12 \%)$ \\
\hline
\end{tabular}

${ }^{*}$ Each value is representative of the mean $\pm \% R S D$ of $n$ observations. For the determination of intermediate precision, $n$ is $3 . \% \mathrm{RSD}$ denotes the percentage standard deviation.

The specificity of the method was tested by analyzing the prepared sample solutions which contained typical formulation excipients. Fig.2 depicts the chromatograms obtained for clarithromycin standard and sample solutions while, fig. 3 depicts the chromatograms obtained for spiramycin standard solution and the sample solution prepared in combination with the mentioned excipients. No peak interference of any of the excipients was observed and therefore the method was deemed suitable for the analysis of formulated dosage forms containing either of the macrolides. The presented results show that the developed method is accurate, precise and specific. A simple HPLC method was developed and validated for the detection and quantification of either clarithromycin or spiramycin. The method proved to be accurate and reproducible and to be suitable for the analysis of either clarithromycin or spiramycin either as bulk drug or when in combination with typical pharmaceutical excipients.

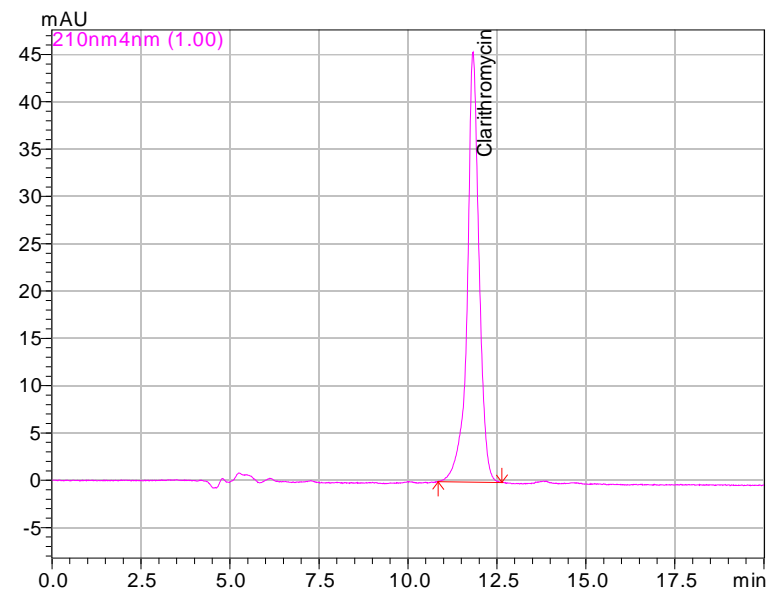

(a)

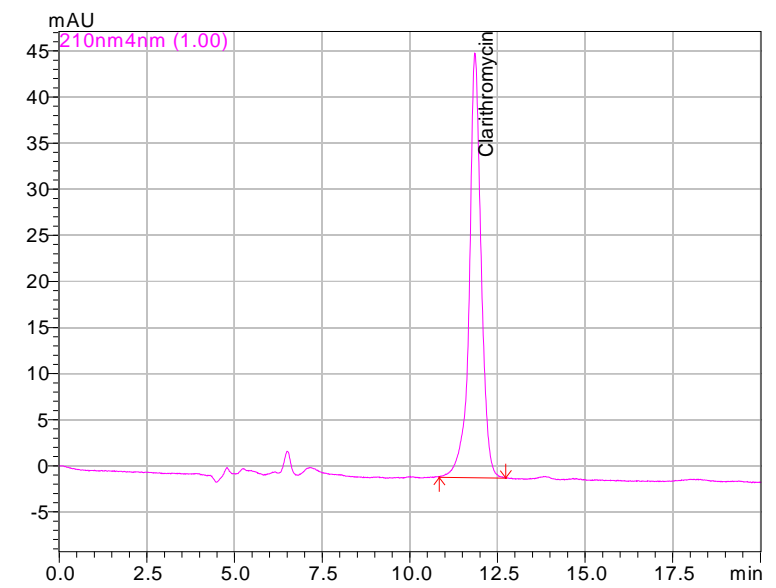

(b)

Fig. 2: Chromatograms obtained for clarithromycin during specificity testing with chromatogram (a) showing the peak obtained for clarithromycin from a standard solution and (b) showing the peak obtained for clarithromycin detected from a commercial sample

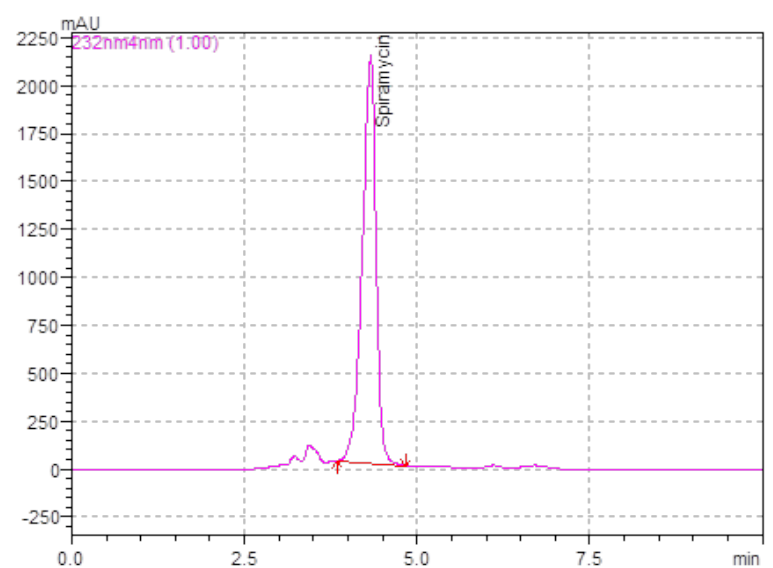

(a)

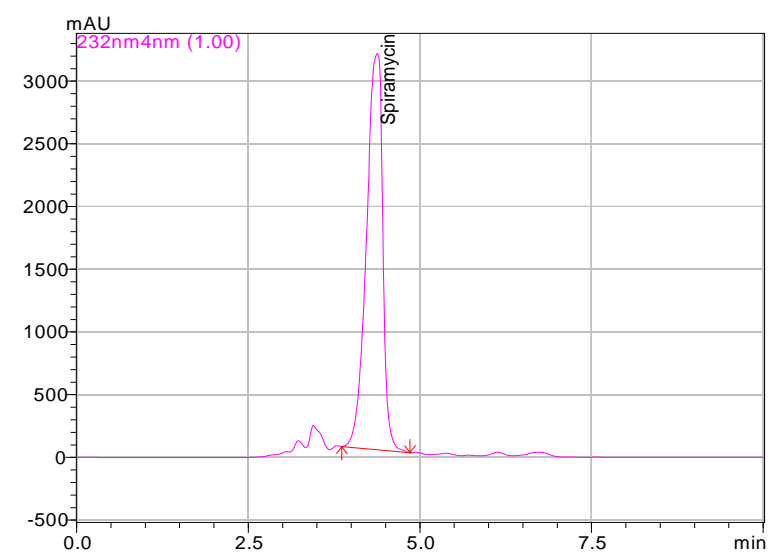

(b)

Fig. 3: Chromatograms obtained for spiramycin during specificity testing with chromatogram (a) showing the peak obtained for spiramycin from a standard solution and (b) showing the peak obtained for spiramycin detected from a commercial sample

\section{ACKNOWLEDGEMENT}

This work was carried out with the financial support of the National Research Foundation of South Africa (NRF) (Grant no. TTK13020718661) and the Centre of Excellence for Pharmaceutical Sciences, (Pharmacen) of the North-West University, Potchefstroom Campus, South Africa.

\section{CONFLICT OF INTERESTS}

\section{Declared none}

\section{REFERENCES}

1. Iroezindu MO. Disparities in the magnitude of human immunodeficiency virus-related opportunistic infections between high and low/middle-income countries: Is highly active antiretroviral therapy changing the trend? Ann Med Health Sci Res 2016;6:4. 
2. Rubaihayo J, Tumwesigye NM, Konde-Lule J. Trends in the prevalence of selected opportunistic infections associated with HIV/AIDS in Uganda. BMC Infect Dis 2015;15:1.

3. Sepkowitz KA. Opportunistic infections in patients with and patients without acquired immunodeficiency syndrome. Clin Infect Dis 2002;34:1098-107.

4. Davis S. Macrolides and ketolides: more than just antimicrobials. Southeast Asia Psychol J 2011;78:24-7.

5. Sprinz E, Mallman R, Barcellos S, Silbert S, Schestatsky G, Bem David D. AIDS-related cryptosporidial diarrhoea: an open study with roxithromycin. J Antimicrob Chemother 1998;41 Suppl B:85-91.

6. Huang MZ, Li J, Guan L, Li DQ, Nie XM, Gui R, Chen X. Therapeutic effects of acetyl spiramycin and garlicin on cryptosporidiosis among drug users. Int J Parasitol: Drugs Drug Resist 2015;5:185-90.

7. Wang D, Zhang YY. Intestinal pathological changes of Kunming mice infected by Cryptosporidium and the therapeutic efficacy of spiramycin on infected mice. Zhongguoji sheng chongxueyuji sheng chongbingzazhi. Chin J Parasitol Parasitic Diseases 2014;32:225-8.

8. British Pharmacopoeia. The Department of Health. Vol. VI. London: The Stationery office; 2016.

9. United States Pharmacopoeia-39. National Formulary-34; Pharmacopeial forum; 2016. p. 8027.
10. Li W, Jia H, Zhao K. Determination of clarithromycin in rat plasma by HPLC-UV method with pre-column derivatization. Talanta 2007;71:385-90.

11. Maher HM, Youssef RM, Khalil RH, El-Bahr SM. Simultaneous multi-residue determination of metronidazole and spiramycin in fish muscle using high-performance liquid chromatography with UV detection. J Chromatogr B 2008;876:175-81.

12. Oka H, Harada KI, Suzuki M, Ito Y. Separation of spiramycin components using high-speed counter-current chromatography. J Chromatogr A 2000;903:93-8.

13. Wang MJ, Pendela M, Hu CQ, Jin SH, Hoogmartens J, Van Schepdael A, et al. Impurity profiling of acetyl spiramycin by liquid chromatography-ion trap mass spectrometry. J Chromatogr A 2010;1217:6531-44.

14. http://www.ich.org/fileadmin/Public_Web_Site/ICH_Products /Guidelines/Quality/Q2_R1/Step4/Q2_R1_Guideline.pdf. [Last accessed on 25 Aug 2016].

\section{How to cite this article}

- $\quad$ Runako Masline Katsidzira, Anita Wessels, Marique Aucamp. A novel RP-HPLC method for the detection and quantification of clarithromycin or spiramycin in bulk drug samples and dosage forms. Int J Pharm Pharm Sci 2016;8(12):310-313. 